\title{
Surgical techniques of video-assisted thoracic surgery for congenital pulmonary airway malformation in a 1-year-3-month-old $(8.6 \mathrm{~kg})$ infant
}

\author{
Atsushi Ito ${ }^{1}$, Shinji Kaneda ${ }^{1}$, Akira Shimamoto ${ }^{1}$, Kohei Matsushita ${ }^{2}$, Yuhki Koike ${ }^{2}$, Mikihiro Inoue ${ }^{2}$, \\ Keiichi Uchida ${ }^{2}$, Motoshi Takao ${ }^{1}$ \\ ${ }^{1}$ Department of Thoracic and Cardiovascular Surgery, Mie University Graduate School of Medicine, Edobashi, Tsu, Japan; ${ }^{2}$ Department of \\ Gastrointestinal and Pediatric Surgery, Mie University Graduate School of Medicine, Edobashi, Tsu, Japan \\ Correspondence to: Atsushi Ito, MD. Department of Thoracic and Cardiovascular Surgery, Mie University Graduate School of Medicine, 2-174 \\ Edobashi, Tsu, Mie 514-8507, Japan. Email: i-atsushi@clin.medic.mie-u.ac.jp.
}

\begin{abstract}
We herein report a 1-year-3-month-old boy $(8.6 \mathrm{~kg})$ with asymptomatic congenital pulmonary airway malformation (CPAM). The patient had been prenatally diagnosed with CPAM. Since his neonatal condition was stable, surgery was electively planned once he reached 1 year of age. Preoperative chest computed tomography (CT) revealed a multiseptated air-filled cystic lesions in the left lower lobe. Complete video-assisted thoracic surgery (C-VATS) with left lower lobectomy was performed (operation time: $182 \mathrm{~min}$, blood loss: $10 \mathrm{~mL}$ ). The patient was discharged on postoperative day 7 with no complications. The pathological examination revealed a type 2 CPAM (Stocker's classification). Although we believe VATS lobectomy for CPAM in infants is feasible, there are some specific hints and pitfalls to be aware of when performing pediatric thoracic surgery: (I) study and improve upon the ligation technique of vessels and bronchus, (II) be aware of the anatomical location of vessels and bronchus, and (III) adjust the position of the bronchial blocker for differential ventilation. When the condition of patients is stable without any symptoms or infection, we recommend that they undergo surgery after the age of one to ensure appropriate growth. In addition, we propose that C-VATS lobectomy may be feasible if patients are older than 18 months old or weigh more than $10 \mathrm{~kg}$ from the perspective of vessel/bronchial dissection technique and differential ventilation during anesthesia.
\end{abstract}

Keywords: Congenital pulmonary airway malformation (CPAM); video-assisted thoracic surgery (VATS); infant

Received: 29 March 2020; Accepted: 25 December 2020; Published: 25 February 2022.

doi: $10.21037 /$ ccts-20-68

View this article at: http://dx.doi.org/10.21037/ccts-20-68

\section{Introduction}

Congenital pulmonary airway malformation (CPAM) is a disease in which bronchioles abnormally proliferate and form various-sized cysts in the fetal period (1). Surgical resection is the standard care for symptomatic CPAM; however, the management of asymptomatic CPAM remains controversial. Although the morbidity and mortality of surgery should be taken into account, many series recommended early surgical resection to avoid the eventual development of complications, such as recurrent infections, spontaneous pneumothorax, or even the rare development of lung malignancy (2).

Recently, thoracoscopic surgery for asymptomatic patients with CPAM during infancy has been frequently performed, and most reports have described high success rates without significant postoperative complication (3). We previously reported that thoracoscopic surgery might be feasible in patients older than 18 months or weighing more than $10 \mathrm{~kg}$ from the perspective of the vessel/bronchial dissection technique and differential ventilation during anesthesia (4). Although some reports have recommended that surgical intervention be performed earlier than our 

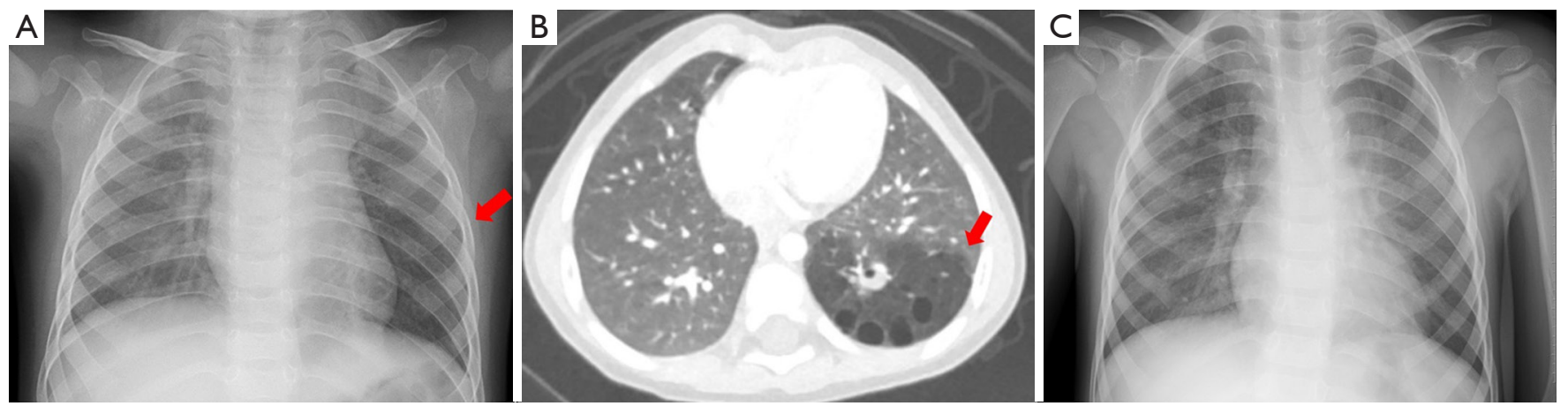

Figure 1 A 1-year-3-month-old boy with type 2 CPAM. (A) Chest radiography showed a low-attenuation area in the left lower lung field (arrow); (B) chest CT revealed multi-septated, air-filled cystic lesions in the left lower lobe (arrow); (C) postoperative chest radiography showed good expansion of the left upper lobe (9 months after surgery). CPAM, congenital pulmonary airway malformation; CT, computed tomography.

recommendation $(5,6)$, thoracoscopic resection should be avoided if there are technical difficulties, since bleeding from the pulmonary artery $(\mathrm{PA})$ can be fatal in pediatric surgery.

We herein report our surgical experience of complete video-assisted thoracic surgery (C-VATS) with left lower lobectomy for CPAM in a 1-year-3-month-old boy $(8.6 \mathrm{~kg})$ and introduce some specific hints and pitfalls to be aware of when performing pediatric thoracic surgery. All procedures performed in this study were in accordance with the ethical standards of the institutional and/or national research committee(s), and with the Helsinki Declaration (as revised in 2013). Written informed consent was obtained from the patient's parent or legal guardian for publication of this study and accompanying images. A copy of the written consent is available for review by the editorial office of this journal.

\section{Clinical summary}

We herein report a 1-year-3-month-old boy $(8.6 \mathrm{~kg})$ with asymptomatic CPAM in the left lower lobe. The patient had been prenatally diagnosed with CPAM. Since his neonatal condition was stable, surgery was electively planned once he reached 1 year of age.

The preoperative chest radiograph showed a lowattenuation area in the left lower lung field (Figure 1A). Chest computed tomography (CT) revealed a multiseptated air-filled cystic lesions of segmental lung tissue with abnormal bronchial proliferation in the left lobe (Figure $1 B)$. After the assessment of the general condition and comorbidities, we performed left lower lobectomy by threeport complete VATS (operation time: $182 \mathrm{~min}$, blood loss: $10 \mathrm{~mL}$ ). The patient had no postoperative complications, and the postoperative chest radiography showed good expansion of the left upper lobe (Figure 1C). The chest drainage tube was removed on the fourth postoperative day and the patient discharged on the seventh postoperative day. The pathological examination revealed a type 2 CPAM (Stocker's classification).

\section{Surgical technique}

\section{Anesthesia, port placement and surgical instrument}

The patient was positioned in a right lateral decubitus position and intubated by a single-lumen endotracheal tube with a bronchial blocker (Arndt Endobronchial Blocker; COOK Medical, Indiana, USA) for differential ventilation. Complete VATS lobectomy was performed through a 3-cm access window at the $5^{\text {th }}$ intercostal space in the anterior axillary line, a $1-\mathrm{cm}$ assist port at the $6^{\text {th }}$ intercostal space in the posterior axillary line and a $0.5-\mathrm{cm}$ camera port at the $8^{\text {th }}$ intercostal space in the middle axillary line. Since surgical instruments meant for adults cannot be used in infants, we selected the three-part dismantling CLICK line series for pediatric laparoscopic surgery (Karl Stortz Inc., Tuttlingen, Germany), a LigaSure ${ }^{\mathrm{TM}}$ Maryland Jaw $23 \mathrm{~cm}$ (Covidien, Mansfield, MA, USA) and a $5-\mathrm{mm}$ rigid endoscope. Intraoperative differential ventilation is also essential for the adequate visualization and exposure of the other lung, especially during the thoracoscopic approach; this was previously described in detail (4). 


\section{Left lower lobectomy (Video 1)}

(I) After division of the inferior pulmonary ligament by electrocautery scissors, the inferior pulmonary vein (IPV) was exposed (Figure $2 A$ ). The dissection continued by division of the mediastinal pleura around the pulmonary hilum.

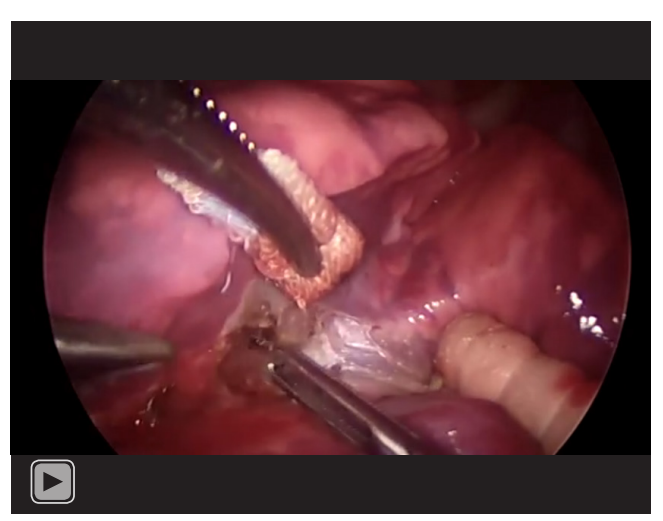

Video 1 Left lower lobectomy of a 1-year-3-month-old boy was performed by 3-port complete video-assisted thoracic surgery (VATS).
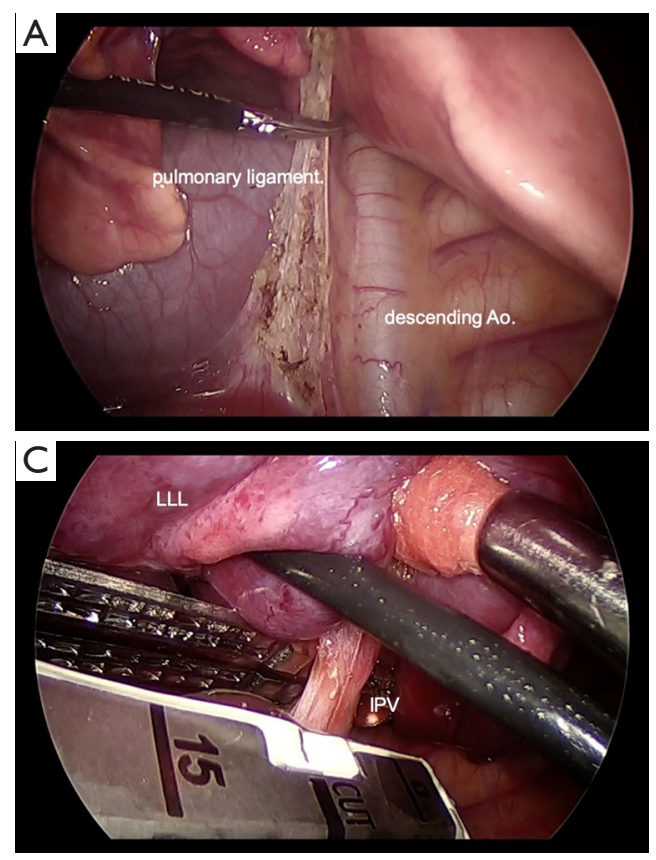

(II) Next, the interlobar PA was visualized after dividing the poorly lobulated interlobar fissure (Figure 2B). The left lower bronchus was identified from the posterior mediastinum. The upper oblique fissure $(\mathrm{S} 1+2 / \mathrm{S} 6)$ was tunneled and dissected with a (white cartridge $35-\mathrm{mm}$ ) endo-stapler (Powered ECHELON FLEX 7; Ethicon Endo-Surgery, Cincinnati, OH, USA).

(III) Subsequently, the exposed IPV was encircled and dissected with the same endo-stapler (Figure 2C). The lower bronchus was exposed by retracting the distal stump of the IPV cranially.

(IV) Considering anatomical variability, each segmental branch (A6: superior segmental artery, A8: ventral basal segmental artery, A9+10: dorsolateral basal segmental artery) of the interlobar PA was isolated, ligated and dissected with a LigaSure ${ }^{\mathrm{TM}}$ Maryland Jaw (Figure 2D). The lower bronchus was stapled with the same endo-stapler.

(V) The lower oblique fissure (lingular/S8) was stapled with the same endo-stapler. After completing lobectomy, the specimen was removed in a protective bag (Inzii retrieval system; Applied Medical, Rancho
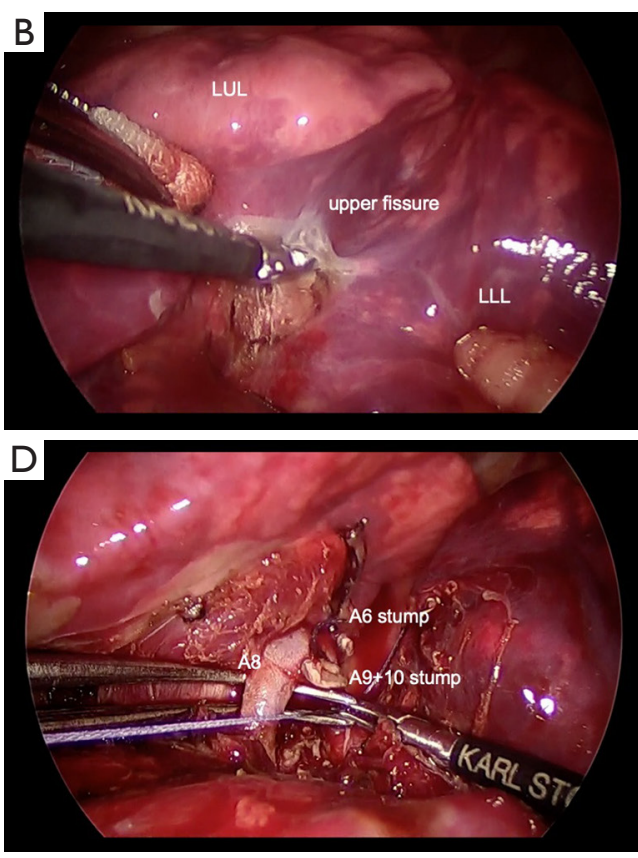

Figure 2 The three-port complete VATS lobectomy procedures. (A) Division of the inferior pulmonary ligament by electrocautery scissors; (B) division of the poorly lobulated interlobar fissure; (C) the exposed IPV was dissected with the endo-stapler; (D) each segmental branch (A6, A8, A9+10) of the interlobar PA was isolated, ligated and dissected. VATS, video-assisted thoracic surgery; PA, pulmonary artery; IPV, inferior pulmonary vein. LUL, left upper lobe; LLL, left lower lobe. 
Santa Margarita, CA, USA) through the 3 -cm access window.

(VI) Finally, the lung was re-expanded for air leakage testing. Fibrin glue and a polyglycolic acid sheet were applied to the interlobar resection margin to avoid postoperative air leakage. A single 9-F Blake silicon drain was placed in the thoracic cavity through the 5-mm camera port.

\section{Comments}

Surgical management of asymptomatic CPAM is a highly contested issue in pediatric thoracic surgery. Despite several studies, the timing of surgical treatment and resection procedures has not been clearly defined. Asymptomatic infant patients with CPAM need surgery to prevent infection and malignant conversion of the cystic wall. Wong et al. reported that nearly all asymptomatic patients with CPAM at birth develop symptoms by their later pre-school years or even during adolescence (7). In addition, Takeda et al. reported that infants tolerate lobectomy extremely well with compensatory lung growth, resulting in the total lung volume and gas exchange capacity returning to near normal during somatic maturation (8).

For the above reasons, when the condition of patients is stable without any symptoms or infection, we recommend that they undergo surgery after the age of one to ensure appropriate growth. In addition, we propose that C-VATS lobectomy may be feasible if patients are older than 18 months old or weigh more than $10 \mathrm{~kg}$ from the perspective of vessel/bronchial dissection technique and differential ventilation during anesthesia (4).

C-VATS lobectomy during infancy is an ideal option for asymptomatic patients with CPAM, and some reports have noted high success rates without significant postoperative complications $(3,9)$. In addition, Mattioli et al. emphasized the superiority of thoracoscopic surgery in terms of both the length of postoperative hospitalization compared with thoracotomy and the fact that thoracotomy might induce thoracic deformation and scoliosis thereafter (10).

However, thoracoscopic surgery should be performed with a great deal of caution, since intraoperative issues, such as bleeding from the PA, can be fatal, especially in pediatric surgery. Several hints and pitfalls concerning surgical procedures are described below.

* Unlike thoracoscopic surgery of adults, it might be difficult to use an endo-stapler and the energy device due to the small size of the thoracic cavity of infants. Therefore, surgeons must carefully study and attempt to improve their ligation techniques for blood vessels and the bronchus.

* In adults, the lymph nodes are often used as an indicator of interlobar fissure and bronchial location. However, the lymph nodes of infants are difficult to distinguish from connective tissue. Therefore, it is necessary to be familiar with the anatomical location of vessels and the bronchus.

* It is important to work with the anesthesiologist to adjust the position of the bronchial blocker for differential ventilation, as the tip of the bronchial blocker might easily shift due to the surgical procedure. In particular, special care should be taken to avoid stapling the bronchial blocker while the bronchus is dissected with an endo-stapler.

Although lobectomy is the standard procedure in CPAM, anatomical segmentectomy might be a viable alternative in select cases in which the cystic lesions have spread to multiple lobes, in order to avoid pneumonectomy. In most cases, non-anatomical resection seems unsuitable, as some of the disease is microscopic and not grossly visible, making complete resection difficult (11). However, anatomical segmentectomy is applicable only when preoperative imaging and gross findings at the time of surgery shows the cystic lesion to be limited to the segment targeted for resection $(11,12)$.

Compared to adults, children are at a greater risk for developing radiation-associated cancer (13), and indeed, radiation exposure in children needs to be kept in mind; however, we believe that CT is necessary for the accurate assessment of cystic lesion in CPAM. Particularly in children, the preoperative CT findings are often unclear due to incomplete breath holding during CT performance. In such cases, sedation during CT and high-speed imaging with helical CT are promising approaches.

In cases of anatomical segmentectomy and incomplete pulmonary fissure, considering the risk of residual lesion caused by difficulty with the precise macroscopic identification of the normal lung border, the intravenous injection of indocyanine green may be used in order to accurately dissect the correct segmental plane without leaving a cystic remnant (14).

We performed left lower lobectomy with three-port VATS in the present case because our standard procedure is a three-port VATS procedure. As uni-portal VATS has become more popular in recent years (15), surgical resection for treatment of CPAM may also be performed by a uni- 
portal VATS approach. However, the safety and indication of uni-portal VATS for CPAM remain controversial, so this approach should be evaluated in future studies.

In summary, based on our clinical experience, we believe that complete VATS lobectomy for CPAM in infants is a safe and effective surgical treatment.

\section{Acknowledgments}

The video was awarded second prize in the First International Lung Surgery Competition (2019 Masters of Lung Surgery).

Funding: None.

\section{Footnote}

Peer Review File: Available at https://ccts.amegroups.com/ article/view/10.21037/ccts-20-68/prf

Conflicts of Interest: All authors have completed the ICMJE uniform disclosure form (available at https://ccts. amegroups.com/article/view/10.21037/ccts-20-68/coif). The authors have no conflicts of interest to declare.

Ethical Statement: The authors are accountable for all aspects of the work in ensuring that questions related to the accuracy or integrity of any part of the work are appropriately investigated and resolved. All procedures performed in this study were in accordance with the ethical standards of the institutional and/or national research committee(s), and with the Helsinki Declaration (as revised in 2013). Written informed consent was obtained from the patient's parent or legal guardian for publication of this study and accompanying images. A copy of the written consent is available for review by the editorial office of this journal.

Open Access Statement: This is an Open Access article distributed in accordance with the Creative Commons Attribution-NonCommercial-NoDerivs 4.0 International License (CC BY-NC-ND 4.0), which permits the noncommercial replication and distribution of the article with the strict proviso that no changes or edits are made and the original work is properly cited (including links to both the formal publication through the relevant DOI and the license). See: https://creativecommons.org/ licenses/by-nc-nd/4.0/.

\section{References}

1. Stocker JT. Congenital pulmonary airway malformation: a new name for and an expanded classification of congenital cystic adenomatoid malformation of the lung. Histopathology 2002;41:424-30.

2. Aziz D, Langer JC, Tuuha SE, et al. Perinatally diagnosed asymptomatic congenital cystic adenomatoid malformation: to resect or not? J Pediatr Surg 2004;39:329-34.

3. Kunisaki SM, Powelson IA, Haydar B, et al. Thoracoscopic vs open lobectomy in infants and young children with congenital lung malformations. J Am Coll Surg 2014;218:261-70.

4. Ito A, Takao M, Shimamoto A, et al. Introduction of thoracoscopic surgery for congenital pulmonary airway malformation in infants: review of 13 consecutive surgical cases. J Thorac Dis 2019;11:5079-86.

5. Style CC, Cass DL, Verla MA, et al. Early vs late resection of asymptomatic congenital lung malformations. J Pediatr Surg 2019;54:70-4.

6. Jelin EB, O'Hare EM, Jancelewicz T, et al. Optimal timing for elective resection of asymptomatic congenital pulmonary airway malformations. J Pediatr Surg 2018;53:1001-5.

7. Wong A, Vieten D, Singh S, et al. Long-term outcome of asymptomatic patients with congenital cystic adenomatoid malformation. Pediatr Surg Int 2009;25:479-85.

8. Takeda S, Miyoshi S, Inoue M, et al. Clinical spectrum of congenital cystic disease of the lung in children. Eur J Cardiothorac Surg 1999;15:11-7.

9. Nasr A, Bass J. Thoracoscopic vs open resection of congenital lung lesions: a meta-analysis. J Pediatr Surg 2012;47:857-61.

10. Mattioli G, Pio L, Disma NM, et al. Congenital Lung Malformations: Shifting from Open to Thoracoscopic Surgery. Pediatr Neonatol 2016;57:463-6.

11. Macchini F. Thoracoscopic resection of congenital pulmonary airway malformations: timing and technical aspects. J Thorac Dis 2020;12:3944-8.

12. Rothenberg SS, Shipman K, Kay S, et al. Thoracoscopic segmentectomy for congenital and acquired pulmonary disease: a case for lungsparing surgery. J Laparoendosc Adv Surg Tech A 2014;24:50-4.

13. Chodick G, Kim KP, Shwarz M, et al. Radiation risks from pediatric computed tomography scanning. Pediatr Endocrinol Rev 2009;7:29-36. 
14. Ito A, Takao M, Shimamoto A, et al. Prolonged intravenous indocyanine green visualization by temporary pulmonary vein clamping: realtime intraoperative fluorescence image guide for thoracoscopic anatomical segmentectomy. Eur J
Cardiothorac Surg 2017;52:1225-6.

15. Guido-Guerrero W, Bolaños-Cubillo A, GonzálezRivas D. Single-port video-assisted thoracic surgery (VATS)-advanced procedures \& update. J Thorac Dis 2018;10:S1652-61.

doi: $10.21037 /$ ccts-20-68

Cite this article as: Ito A, Kaneda S, Shimamoto A, Matsushita K, Koike Y, Inoue M, Uchida K, Takao M. Surgical techniques of video-assisted thoracic surgery for congenital pulmonary airway malformation in a 1-year-3-month-old $(8.6 \mathrm{~kg})$ infant. Curr Chall Thorac Surg 2022;4:9. 